\title{
Relapsing intracranial Rosai-Dorfman disease
}

\author{
A Petzold, M Thom, M Powell, GT Plant
}

\begin{abstract}
Two patients presenting with recurrent visual impairment due to relapsing intracranial Rosai-Dorfman disease are described. In both patients a preoperative diagnosis of meningioma was made. Histological examination disclosed the characteristic picture of $\mathrm{S} 100$ and $\mathrm{CD68}$ positive histiocytosis with prominent lymphophagocytosis. In both patients complete tumour removal by surgery was impossible with residual tissue being the origin of relapsing disease. Low dose radiation led to partial recovery of vision and resolution of the intracranial mass. Review of the literature on intracranial Rosai-Dorfman disease leads to the suggestion that postoperative radiotherapy may be advisable in all cases.

(F Neurol Neurosurg Psychiatry 2001;71:538-541)
\end{abstract}

Keywords: Rosai-Dorfman; sinus histiocytosis; multiple meningioma; intracranial neoplasms

Department of Neuroimmunology, Institute of Neurology, Queen Square, London WC1N 3BG and Moorfields Eye Hospital, City Road, London EC1 2PD, UK A Petzold

Department of Neuropathology, Institute of Neurology M Thom

Department of Neurosurgery, National Hospital for

Neurology and

Neurosurgery

M Powell

Moorfields Eye

Hospital and National

Hospital for Neurology and Neurosurgery

GT Plant

Correspondence to:

Dr A Petzold

a.petzold@ion.ucl.ac.uk

Received 29 December 2000 and in revised form

24 April 2001

Accepted 24 April 2001
Rosai-Dorfman disease or sinus histiocytosis is a histiocytic proliferative disorder. ${ }^{1}$ Generally patients present in their mid-20s with cervical lymphadenopathy $(87 \%)$, often preceded by a short non-specific infection. ${ }^{2}$ Extranodal involvement occurs in $25 \%$ to $43 \%^{2-4}$ and affects the skin $(12 \%)$, paranasal sinuses $(11 \%)$, soft tissue $(9 \%)$, bone $(9 \%)$, salivary gland $(5 \%)$, oral cavity $(3 \%)$, kidney $(2 \%)$, lower respiratory tract $(2 \%)$, larynx $(1 \%)$, and, rarely, other locations. ${ }^{2}$ Intracranial lesions are extremely rare. To our knowledge 32 patients with intracranial masses have been described previously ${ }^{3-30}$ including three with suprasellar lesions. ${ }^{9}{ }^{10} 16$ Eight patients experienced visual impairment, ${ }^{3-11}$ which was the presenting sign in six of them. ${ }^{5-10}$ This report follows up the patient of Bhattacharjee et $a l^{9}$ which was reported in this fournal not having relapsed after surgery. A relapse, however, occurred after publication and we report the 11 year follow up, together with a second patient, in which recurrence also occurred.

\section{Patient 1}

A 78 year old retired Welsh farmer presented at Moorfields Eye Hospital in June 1989 with progressive bilateral visual impairment. $\mathrm{He}$ underwent bifrontal craniotomy with subtotal tumour resection. His condition remained stable until January $1990 .^{9}$ The patient presented, however, with further impaired vision in February 1990 and the MRI disclosed evidence of local recurrence of the mass around both optic nerves, which enhanced with gadolinium on $\mathrm{T} 1$ axial brain scans. His visual acuity had declined to $6 / 24, \mathrm{~N} 24$ and 2/13 Ishihara plates on the right; counting fingers at $1 \mathrm{~m}$ and only the Ishihara control plate on the left. In addition to the previous bitemporal hemianopia the left nasal field had decreased to a small "island of vision". Both fundi showed loss of nerve fibre layer.

The patient underwent low dose radiotherapy, after which he showed improvement of his visual acuity to $6 / 18,11 / 17$ Ishihara plates on the right; $6 / 18,16 / 17$ Ishihara plates on the left. He remained clinically stable for the next 10 years. He had diabetes mellitus and a transient ischaemic attack in 1998. In 1999 he complained of some confusion and blurred vision. No further investigation was undertaken. He died of an unknown cause at the age of 89 .

\section{Patient 2}

A 47 year old service engineer with rapidly developing right sided visual loss presented at the National Hospital for Neurology and Neurosurgery in July 1998. Six weeks previously he had complained of visual impairment and was found to have visual acuity of $6 / 24$ on the right. Vision had decreased to light perception only 2 weeks later. On reflection the patient thought the loss of vision had begun 2 years previously. On presentation he had left shoulder pain, weakness in his right leg, fatigue, and frequent headaches starting in the neck and radiating to the occiput. The medical history showed a lumbar disc prolapse 2 years previously.

On examination his visual acuity corrected to 6/6, N12 and 13/13 Ishihara charts correctly identified on the left. No light could be perceived on the right and there was a right afferent pupillary defect. Loss of nerve fibre layer was apparent on the right. Apart from a lateralised Weber test to the right with normal Rinne all other cranial nerves were normal. Sense of smell was not tested at the time. Sensory examination, tone, power and reflexes in the lower limbs were normal. No residual deficit from the previous disc prolapse could be shown. General examination was normal and there was no lymphadenopathy. 
Brain CT at admission showed multiple mass lesions around the foramen magnum, in the chiasmatic cistern arising from the planum sphenoidale, above the cribriform plate, the
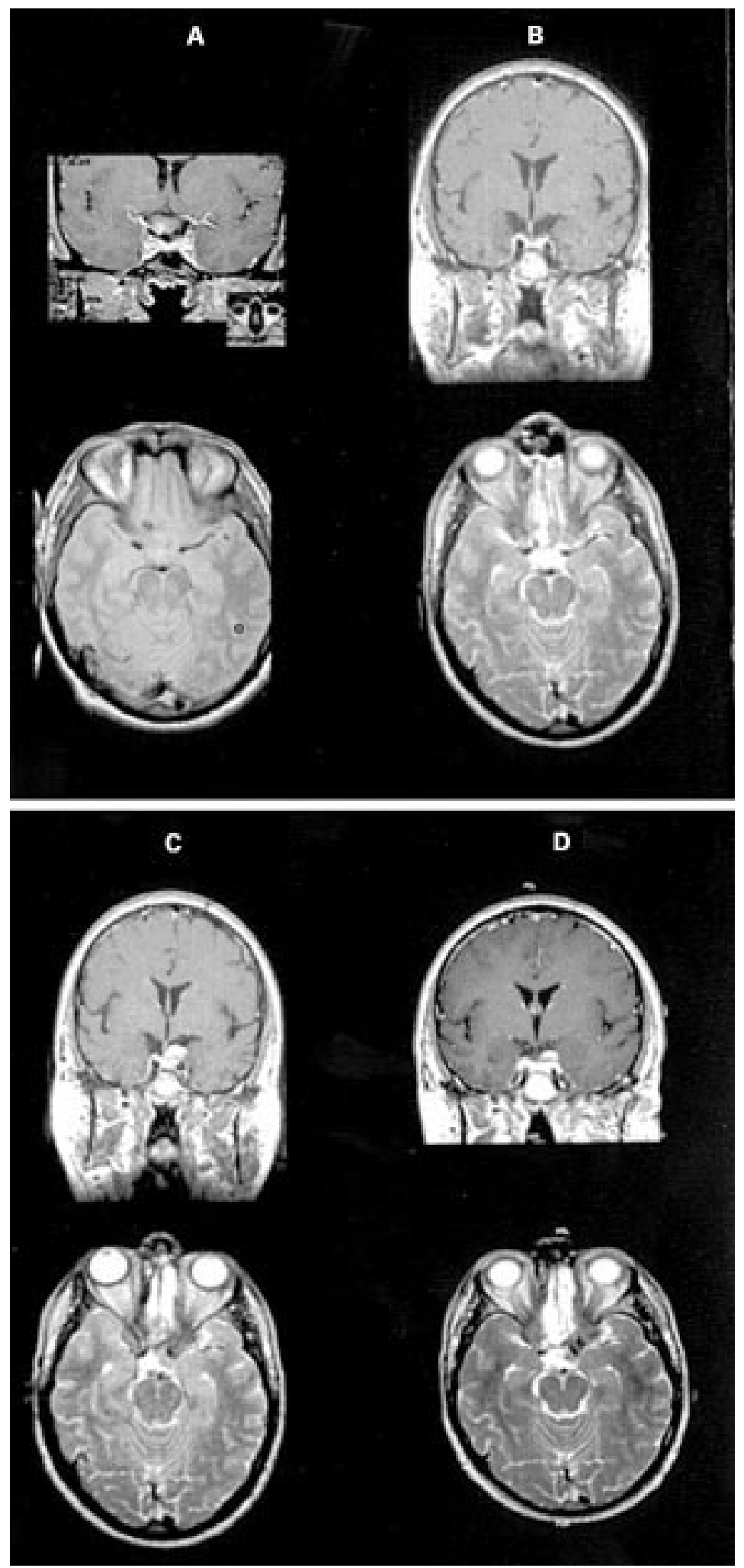

Figure 1 Coronal and axial MRI (post gadolinium) of patient 2. Image (A) shows the sellar lesion preoperatively (17 Fuly 1998). Image (B) displays the postoperative situation with some residual tissue in the region of the optic chiasm (18 August 1998). Image (C) demonstrates tumour regrowth 14 months postoperatively (9 September 1999). Image (D) was taken 6 months after local low dose radiation and shows a decrease of the sellar mass, with some residual tissue. right parafalcine region, and the cerebellopontine angle. These lesions were gadolinium enhancing on the MRI T1 images and suggestive of multiple intracranial neoplasms such as meningioma (fig $1 \mathrm{~A}$ ). Chest radiography was normal for heart and lungs, but the left acromion showed a cystic lesion. No additional skeletal lesions were detected in whole body scintigraphy.

The laboratory investigation showed a decreased concentration of thyroid stimulating hormone $(0.2 \mathrm{mU} / 1$, normal range 0.25-5.0 $\mathrm{mU} / \mathrm{l}$ ) but normal T3 and T4; increased blood glucose $(9.8 \mathrm{mmol} / 1$, normal range 3.3-9.0 $\mathrm{mmol} / \mathrm{l}$ ), and increased white cell count of $14.5 \times 10^{6} / 1$ with $12.8 \times 10^{6} / 1$ neutrophils, $1.2 \times 10^{6} / 1$ lymphocytes, $0.4 \times 10^{6} / 1$ monocytes, and $0.1 \times 10^{6} / 1$ eosinophils. The erythrocyte sedimentation rate was normal $(9 \mathrm{~mm} / \mathrm{h})$.

He underwent subtotal transglabellar resection of the suprasellar mass. The postoperative visual fields showed a small "island of vision" on the right and a superior depressed field on the left. His visual acuity corrected to $6 / 5$ on the left and to finger count on the right. The MRI 1 month after the operation showed some residual gadolinium enhancing tissue around the optic chiasm (fig $1 \mathrm{~B}$ ).

One year later the patient complained of recurrence of the visual symptoms. His visual acuity worsened to $6 / 9$ on the left and to light perception on the right. His sense of smell was now impaired. On MRI the sellar mass had increased in size and extended superiorly, causing bowing of the infundibulum and tilting the optic chiasm (fig $1 \mathrm{C}$ ). The patient underwent radiotherapy (20 Gy over 10 fractions). Three months later visual acuity had improved to counting fingers on the right and $6 / 5$ on the left. His visual fields and colour vision were full on the left. On the right he could perceive hand movements in all quadrants apart from the lower temporal. At 1 year follow up the MRI showed decrease of the sellar mass (fig $1 \mathrm{D}$ ). Some residual tissue could still be seen on the axial images.

\section{HISTOLOGY}

The histology of patient 1 has been discussed in detail by Bhattacharjee et al and has been reviewed by one coauthor (MT); it is identical to that of patient 2 .

For patient 2 histology of the suprasellar dural mass $(30 \times 20 \times 8 \mathrm{~mm})$ showed collagenous tissue with mixed chronic inflammatory cells and numerous polymorphs with very occasional eosinophils. Interspersed within this infiltrate were large cells with vesicular nuclei, some with indented nuclear membranes and abundant cytoplasm. Prominent lymphophagocytosis (fig 2 A) and phagocytosis of neutrophils and red blood cells by these cells was noted. Immunohistochemistry with positive labelling for $\mathrm{S} 100$ (fig $2 \mathrm{~B}$ ) and CD68 (PKM1) and negative staining for CD1a confirmed the histiocytic cell lineage.

\section{Discussion}

Rosai-Dorfman disease or "sinus histiocytosis with massive lymphadenopathy" was initially 

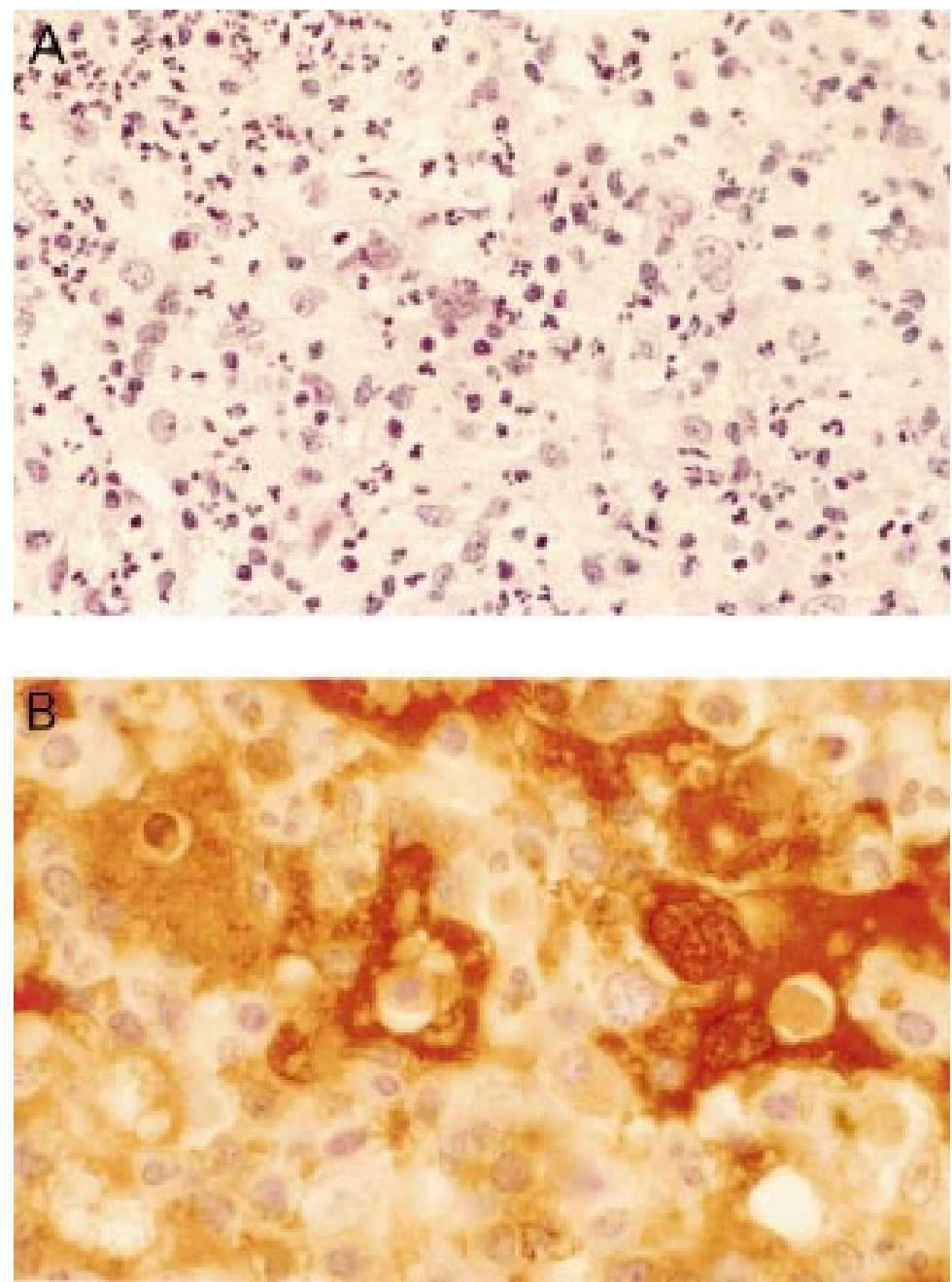

Figure 2 Histology from patient 2. (A) Sheets of histiocytic cells with large vesicular nuclei, some with nuclear indentations, are seen. There is an associated infiltrate of polymorphs and lymphocytes. Lymphophagocytosis (emperiopolesis) by the histiocytic cells is clearly seen (haematoxylin and eosin, original magnification $\times 375$ ). (B) The histiocytic cells show strong nuclear and cytoplasmatic staining with $S 100$ protein and lymphophagocytosis is also seen (S100 immunohistochemistry, original magnification $\times 625$ ).
20.5) reported by Rosai and Dorfman for the entire entity. ${ }^{6}$ Neurological symptoms preceded the diagnosis by a mean of 3 years. Focal neurological signs, seizures, or headache are the most frequent presenting symptoms.

In general, the natural history of nodular sinus histiocytosis has been reported to be benign, with spontaneous remission. If, however, the location of the tumour involves the brain or spinal cord relapsing disease becomes a serious problem.

Intracranial tumor regrowth or recurrence of symptoms has been reported in $14 \%$ (four $^{8} 1222$ out of $29^{3-30}$ ) of patients, excluding our patient $1^{9}$ and two patients who died. ${ }^{6}{ }^{26}$ The mean follow up for these patients was 10.1 years (median 5, range 0.5-30 years). Relapsing patients tended to be slightly older (mean 42 years) without remarkable sex preference (two men, two women). In a further $25 \%$ of patients with CNS involvement no follow up information could be obtained from the literature. ${ }^{6713161824}$ The mean follow up in patients reported as "stable" was 1.5 years (median 1 year, range 1 month-2 years) $)^{3-5} 111_{14}^{19-21}$ 25-30; $^{2}$ but only in $52 \%$ of these patients was brain imaging performed at follow up. ${ }^{3} 4111419202530$

From the surviving 29 patients (17 stable, four relapsing, eight no follow up information available) 18 had no follow up brain imaging at all, five had CT, ${ }^{192225}$ and seven had MRI. ${ }^{3} 41011142030$ Seventy per cent of "stable", patients were male ( 11 male, 5 female). Two patients died, one directly related to disease ( 55 years, female) ${ }^{6}$ and the other one (54 years, female) due to intracerebral haemorrhage after craniotomy. ${ }^{8}$

Surgery was performed in $93 \%$ with the preoperative diagnosis being meningioma. One patient underwent laminectomy for a spinal mass lesion extending from C1-C6. ${ }^{6}$ In one patient transphenoidal biopsy established the diagnosis of intracerebral Rosai-Dorfman disease and radiation ( 1000 cGy in 200 cGy daily) led to tumour resolution at 2 month follow up. ${ }^{30}$ Three patients with spinal involvement (patients 1, 4, and 8 of Foucar et $a l^{6}$ ) received radiation. Patients 1 and 8 also had laminectomy and patient 8 , steroids. Patients 1 and 8 improved with treatment. Patient 4 died 10 years later due to intracranial involvement. ${ }^{6}$ Another case of subtotal surgery with additional radiation (1500 rads) and no relapse at 14 month follow up was reported by Trudel et $a l^{4}$

In summary it seems advisable to ensure a 5 year follow up period (median relapse time) including brain imaging in patients with intracranial Rosai-Dorfman disease. The main preoperative diagnosis remains meningioma, but histology should establish the diagnosis. In cases with subtotal tumour resection or recurrence of neurological symptoms we would treat with local low dose radiation early rather than late. CNS remains, however, rare with 32 reported cases. ${ }^{3-30}$ There is a male predominance of $65.6 \%$ (21 males, 11 females). The mean age is 37 (SD 19) years (range 2-78 years), slightly higher than the 20.6 years (SD
1 Rosai J, Dorfman RF. Sinus histiocytosis with massive lymphadenopathy; a newly recognized clinico-pathological entity. Arch Pathol (Chicago) 1969;82:63-70. 
2 Foucar E, Rosai J, Dorfman R. Sinus histiocytosis with massive lymphadenopathy (Rosai-Dorfman disease): review of sive lymphadenopathy (Rosai-Dorfman disea

$3 \mathrm{Kim} \mathrm{M}$, Provias J, Bernstein M. Rosai-Dorfman disease mimicking multiple meningioma: case report. Neurosurgery 1995;36:1185-7.

4 Shaver EG, Rebsamen SL, Yachnis AT, et al. Isolated extranodal intracranial sinus histiocytosis in a 5 year old boy: case report. F Neurosurg 1993;79:769-73.

5 Lopez P, Estes ML. Immunohistochemical characterization of the histiocytes in sinus histiocytosis with massive lymphadenopathy: analysis of an extranodal case. Human Pathol 1989;20:711-15.

6 Foucar E, Rosai J, Dorfman RF. The neurologic manifestations of sinus histiocytosis with massive lymphadenopathy. Neurology 1982;32:365-71.

7 Song SK, Schwartz IS, Strauchen JA, et al. Meningeal nodules with features of extranodal sinus histiocytosis with massive lymphadenopathy. Am f Surg Pathol 1989;13:406massive 12 .

Wenig BM, Abbondanzo SL, Childers EL, et al. Extranodal sinus histiocytosis with massive lymphadenopathy RosaiDorfman disease) of the head and neck. Human Patho 1993;24:483-92

9 Bhattacharjee MB, Wroe SJ, Harding BN, et al. Sinus histiocytosis with massive lymphadenopathy: isolated suprasellar involvement. F Neurol Neurosurg Psychiatry 1992;55:156-8

10 Woodcock RJ, Mandell JW, Lipper MH. Sinus histiocytosis Rosai-Dorfman disease) of the suprasellar region: MR imaging findings: a case report. Radiology 1999;213:80810.

11 Resnick DK, Johnson BL, Lovely TJ. Rosai-Dorfman disease presenting with multiple orbital and intracranial masses. Acta Neuropathol 1996;91:554-7.

12 Olsen EA, Crawford JR, Vollmer RT. Sinus histiocytosis with massive lymphadenopathy and unusual extranodal manifestations. Am Pathol Lab Med 1988;18:1322-32.

13 Friedman MJ, Rossoff LJ, Aftalion B, et al. Sinus histiocytoFriedman MJ, Rossoff LJ, Aftalion B, et al. Sinus histiocyto-

14 Udono H, Fukuyama K, Okamoto H, et al. Rosai-Dorfman disease presenting multiple intracranial lesions with unique findings on magnetic resonance imaging: case report. $\mathcal{F}$ Neurosurg 1999;91:335-9.

15 Katz DS, Poe LB, Corona RJ. Sinus histiocytosis with massive lymphadenopathy: a case of simultaneous upper respiratory-tract and CNS disease without lymphadenopathy. Am f Neuroradiol 1993;14:219-22.

$16 \mathrm{Ng}$ HK, Poon WS. Sinus histiocytosis with massive lymphadenopathy localized to the sella. $\mathrm{Br} \mathcal{F}$ Neurosurg 1995;9:551-5.
17 Clark WC, Berry, AD. Extranodal sinus histiocytosis with massive lymphadenopathy: isolated central nervous system involvement mimicking meningioma. South Med F 1996;89: 621-3.

18 Panicker NK, Sabhikhi AK, Rai R. Rosai-Dorfman disease presenting as a meningioma. Indian f Cancer 1996;33:1924.

19 Deodhare SS, Ang LC, Bilbao JM. Isolated intracranial involvement in Rosai-Dorfman disease: a report of two cases and review of the literature. Arch Pathol Lab Med 1998;122:161-5.

20 Morandi X, Godey B, Riffaud L, et al. Isolated RosaiDorfman disease of the fourth ventricle: case illustration. $\mathcal{F}$ Neurosurg 2000;92:890.

21 Asai A, Matsutani M, Kohno T, et al. Leptomeningeal and orbital benign lymphophagocytic histiocytosis: case-report. f Neurosurg 1988;69:610-12.

22 Carey MP, Case CP. Sinus histiocytosis with massive lymphadenopathy presenting as a meningioma. Neuropathol Appl Neurobiol 1987;13:391-8.

23 Friendly DS, Font RL, Rao NA. Orbital involvement in sinus histiocytosis. Arch Ophthalmol 1977;95:2006-11.

24 Mir R, Aftalion B, Kahn LB. Sinus histiocytosis with massive lymphadenopathy and unusual extranodal manifestations. Arch Pathol Lab Med 1985;109:867-70.

25 Mirra SS, Tindall SC, Check IJ, et al. Inflammatory meningeal masses of unexplained origin: an ultrastructural and immunological study. 7 Neuropathol Exp Neurol 1983;42: 453-68.

26 Trudel M. Dural involvement in sinus histiocytosis with massive lymphadenopathy: case report. $\mathcal{F}$ Neurosurg 1984 ; 60:850-2.

27 Gaetani P, Tancioni T, Dirocco M, et al. Isolated cerebellar involvement in Rosai-Dorfman disease: case report. Neurosurgery 2000;46:479-81.

28 Huang HY, Huang CC, Lui CC, et al. Isolated intracranial Rosai-Dorfman disease: case report and literature review. Pathol Int 1998;48:396-402.

29 Kudesia S, Shankar SK, Das S, et al. Intracranial plasma cell granuloma: a report of four cases. Neurol India 1998;46: $142-6$.

30 Stromberg JS, Wang AM, Huang TE, et al. Langerhans cell histiocytosis involving the sphenoid sinus and superior orbital fissure. Am $\mathcal{F}$ Neuroradiol 1995;16:964-7.

31 Destombes P. Adénites avec surcharge lipidique, de l'enfant ou de l'adulte jeune, observées aux Antilles et au Mali. Bull Soc Pathol Exot 1965;6:1169-75. 